\title{
Properties and structure of high temperature resistant cyanate ester/polyethersulfone blends using solvent-free toughening approach
}

\author{
Lyaysan Amirova $^{1}$ (D) Fabian Schadt ${ }^{1} \cdot$ Markus Grob $^{1} \cdot$ Christian Brauner $^{1}$. \\ Thomas Ricard ${ }^{2} \cdot$ Tobias Wille $^{3}$
}

Received: 31 August 2020 / Revised: 5 November 2020 / Accepted: 13 November 2020 /

Published online: 25 November 2020

(c) The Author(s) 2020

\begin{abstract}
A high temperature resistant novolac cyanate ester was blended with polyethersulfone (PES) with different molecular weights using the solvent-free approach. The phase separation, curing behavior and thermal properties were studied using hot stage microscopy, differential scanning calorimetry and dynamic mechanical analysis. Results showed the difference in the morphology for blends with different molecular weight PES explained by possible network formation. The influence of PES content on the glass transition temperature and mechanical properties was investigated. The most significant toughening effect (increase of $132 \%$ in fracture toughness) was achieved on a functionalized low molecular weight PES (20 parts per hundred of resin, phr). Rheology investigation allowed to estimate the optimal content of PES (15 phr) for further prepreg manufacturing.
\end{abstract}

Keywords Cyanate ester · Toughening · Polyethersulfone $\cdot$ Phase separation · Glass transition temperature $\cdot$ Fracture toughening

\section{Introduction}

Cyanate ester resins are currently used for many important applications such as high-temperature adhesives, and advanced composite matrices in the aerospace and automotive industry [1-3]. A unique combination of properties such as high temperature stability and chemical resistance, low moisture uptake and low dielectric

Lyaysan Amirova

lyaysan.amirova@fhnw.ch

1 Institute of Polymer Engineering, University of Applied Sciences Northwestern Switzerland, Klosterzelgstrasse 2, 5210 Windisch, Switzerland

2 North Thin Ply Technology, Chemin du Closel 3, 1020 Renens, Switzerland

3 German Aerospace Center, Lilienthalpl. 7, 38108 Braunschweig, Germany 
constant in the cured state, as well as low viscosity in the uncured state (lowest viscosity of all high temperature resins) has led to their use in low-volume highperformance applications. However, their widespread use is unfortunately limited in many applications by their inherent brittle behavior due to their high crosslink density $[4,5]$. The incorporation of thermoplastics into such networks has emerged as a promising approach to improve toughness, especially when high values of elastic moduli and glass transition temperature are required. The most common thermoplastic tougheners for epoxy systems are polysulfones (PSF), polyetherimides (PEI) or polyethersulfones (PES) [6-9].

The process of phase separation during the cure of thermoset/thermoplastic blends is essential to generate the toughened thermosets. The degree of toughening is related to the degree of phase separation and the generated morphologies. The latter depends on curing conditions, molecular weight and content of the thermoplastic toughener $[10,11]$.

PES has been successfully used as a modifier for toughening of epoxy resins [12]. Due to its relatively good compatibility with epoxies, good interfacial bonding between epoxies and PES can be achieved. It was shown that PES, after initial dissolution in the uncured resin, is involved in reaction-induced phase separation during the curing process [13].

Most of the investigated polycyanurate systems in the literature are based on bisphenol A or bisphenol E cyanate esters. Such cyanate esters have a low molecular weight and a glass transition temperature of $250-270{ }^{\circ} \mathrm{C}$. In comparison, novolactype cyanate esters have a high molecular weight and a glass transition temperature above $350{ }^{\circ} \mathrm{C}$, making them favorable for high temperature applications [14]. The challenge in toughening novolac-type cyanate esters is the low solubility of thermoplastic polymers. This is due to the higher polarity and large molecular weight of the novolac-type cyanate esters that limits the range of possible tougheners. Moreover, in most of the existing research works, to achieve the dissolution of thermoplastic toughener, solvents are usually used with further evaporation. For industrial applications, this approach is not suitable; therefore, we focused on simplification of toughening procedure. From our preliminary investigations, we established that a number of thermoplastic polymers (PEI, PSF) are not enough soluble using the solvent-free toughening approach and do not lead to phase separation while PES showed very promising results.

Therefore, the aim of the present study was to investigate the influence of molecular weight, functionalization and content of PES on the morphology and phase separation behavior as well as on thermal and mechanical properties of novolac-type cyanate ester composites.

\section{Experimental}

\section{Materials}

In this work, phenol novolac cyanate ester (CE, monomer molar mass $381.39 \mathrm{~g} / \mathrm{mol}$ ) was used as a matrix, the manufacturer is not mentioned according to the project 
partner requirements. As tougheners different polyethersulfones Sumikaexel 2603 MP, 4100 MP and 5003 MP (Sumitomo Chemicals; Japan) with various molecular weights were used. The properties of used materials are presented in Table 1.

\section{Sample preparation}

Cyanate ester/PES blends were prepared as follows. The viscosity of CE was reduced by raising the temperature to $80{ }^{\circ} \mathrm{C}$. Preliminary dried PES (in vacuum oven $24 \mathrm{~h}$ at $110{ }^{\circ} \mathrm{C}$ ) in amounts of 5, 10, 15, 20 parts per hundred resins (phr) was added to the resin, and mixtures were heated to $180{ }^{\circ} \mathrm{C}$ for $15 \mathrm{~min}$ to achieve swelling of PES particles in the matrix. Using the Speedmixer DAC $1100.1 \mathrm{FVZ}\left(1200 \mathrm{~min}^{-1}\right.$ for $2 \mathrm{~min}$ ), cyanate ester blends with various PES content were obtained.

Plates were manufactured by casting the mixtures into molds consisting of three rectangular steel plaques covered with high temperature resistant release agent Marbocote TRE 45 ECO. The cure cycle was $2 \mathrm{~h}$ at $190{ }^{\circ} \mathrm{C}, 1 \mathrm{~h}$ at $220{ }^{\circ} \mathrm{C}$ and $1 \mathrm{~h}$ at $260{ }^{\circ} \mathrm{C}$. The cured plates were allowed to cool slowly to room temperature, removed from the mold and further cut to produce bars for mechanical testing.

\section{Methods}

\section{Differential scanning calorimetry (DSC)}

Dynamical DSC measurements were performed using a TA DSC 25 (TA Instruments) at a heating rate of $10 \mathrm{~K} / \mathrm{min}$ purged with dry nitrogen gas.

\section{Morphology observation}

The morphology of blends was observed using a Linkam Hot Stage microscope. Resin droplets were placed in between two glass plates and placed on the hot stage. The temperature was then raised to $190{ }^{\circ} \mathrm{C}$, kept for $15 \mathrm{~min}$, and then further increased for post-curing to $260{ }^{\circ} \mathrm{C}$ for $30 \mathrm{~min}$.

Fracture surface investigation was performed using a Keyence VK-X200 confocal laser scanning microscope (CSLM).

Table 1 Material properties of used PES

\begin{tabular}{llll}
\hline Parameter & PES 2603MP & PES 4100MP & PES 5003MP \\
\hline Molar mass, g/mol & 16,000 & 33,000 & 42,000 \\
Particle size, $\mu \mathrm{m}$ & 45 & 45 & 45 \\
Glass transition temperature, ${ }^{\circ} \mathrm{C}$ & 220 & 223 & 227 \\
-OH end groups, per 100 polymer relat- & 4.5 & - & 1.1 \\
$\quad$ ing units & & & \\
\hline
\end{tabular}




\section{Rheology}

The viscosity of CE/PES blends was measured at elevated temperatures between 25 and $120{ }^{\circ} \mathrm{C}$ using Physica MCR300 (Anton Paar) plate-plate rheometer at $0.1 \%$ strain and $1 \mathrm{~Hz}$ frequency.

\section{Dynamic mechanical analysis (DMA)}

Glass-transition temperature $T_{\mathrm{g}}$ and Storage Modulus $E$ ' were measured using a TA Q800 dynamic mechanical analyzer (TA Instruments). Measurements were performed using a three-point bending clamp. The specimens were cut with a diamond blade saw and polished to the dimensions of $25 \times 10 \times 2 \mathrm{~mm}$.

The glass transition temperature was defined as the temperature corresponding to the onset of the storage modulus curve.

\section{Mechanical tests}

Fracture toughness tests were performed using single-edge notched bending (SENB) samples in three-point bending, following the ASTM D5045-99(2007). The samples were cut from the resin plates by water jet to nominal dimensions of $52.8 \times 12$ $\times 4 \mathrm{~mm}$ with a $4.5 \mathrm{~mm}$ deep notch. By tapping the samples at the tip of the notch with a frozen razor blade a natural pre-crack was created. The pre-cracked SENB specimens were loaded under three-point bending using a universal testing machine (Zwick/Roell Z100) at a rate of $10 \mathrm{~mm} / \mathrm{min}$. Flexural strength and modulus were determined using the mentioned universal testing machine in three-point bending according to ASTM D790 (2017) with a crosshead speed of $1 \mathrm{~mm} / \mathrm{min}$. The sample dimensions were $50 \times 10 \times 3 \mathrm{~mm}$.

\section{Results and discussion}

\section{Thermal properties}

DCS results (Fig. 1) show an exothermic reaction at a curing temperature of around $300{ }^{\circ} \mathrm{C}$. Temperature of curing peak $(T p)$ and total enthalpy of the reaction $(\Delta H)$ are collected in Table 2. Comparing the results, it is noticeable that the PES (PES2603MP and PES5003MP) with OH-end groups accelerate the curing of CE. PES without hydroxyl groups (PES4100MP) has almost no influence on the curing process (Table 2). Blends with both functionalized PES have lower enthalpy, because $\mathrm{OH}$ groups are involved in the curing process of the cyanate ester.

\section{Morphological characterization}

Morphology of CE-PES blends for $15 \mathrm{phr}$ of toughener is presented in Fig. 2. All samples exhibited initial dissolution in the matrix, followed by phase 


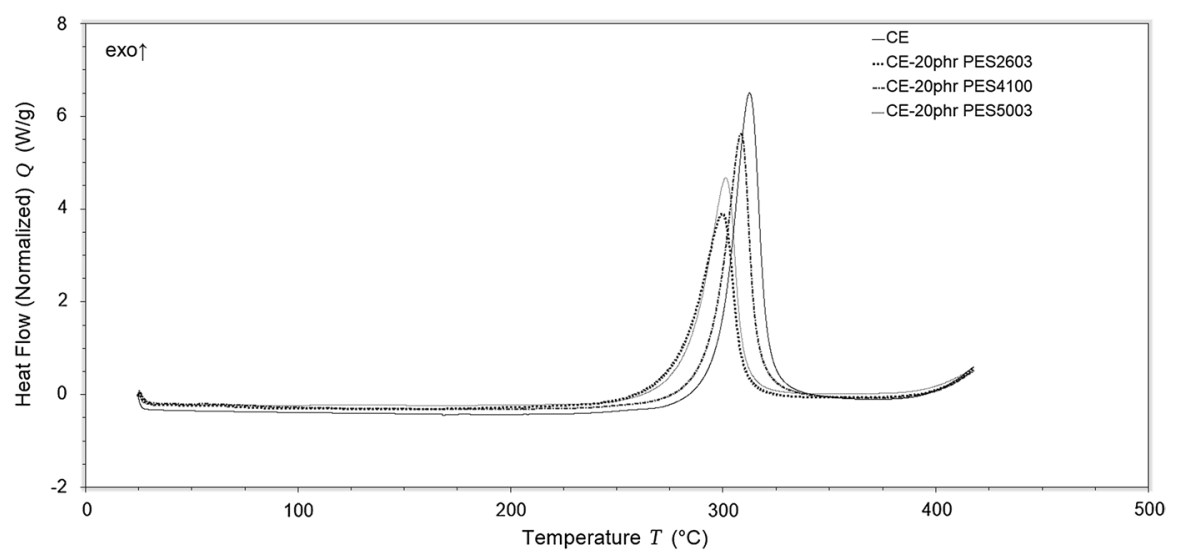

Fig. 1 DSC curves of CE with 20 phr of PES 2603MP, 4100MP and 5003MP

Table 2 Curing parameters of neat CE and 20 phr of PES blends

\begin{tabular}{lll}
\hline System & $T p,{ }^{\circ} \mathrm{C}$ & $\Delta \mathrm{H} \mathrm{103, \textrm {J } / \mathrm { kg }}$ \\
\hline $\mathrm{CE}$ & 313 & $710.8 \pm 17.2$ \\
CE-PES 2603MP & 300 & $555.2 \pm 44.9$ \\
CE-PES 4100MP & 309 & $615.4 \pm 38.1$ \\
CE-PES 5003MP & 301 & $569.1 \pm 40.7$ \\
\hline
\end{tabular}

separation. However, only PES with low molecular weight (PES2603MP) forms a dual droplet morphology with spherical domains of approximately 5-20 $\mu \mathrm{m}$ diameter (Fig. 2a). Toughener with higher molecular weight and terminate hydroxyl groups (PES5003MP) formed co-continuous sea island morphology with a combined CE/PES structure after dissolution (Fig. 2c). Non-functionalized PES (PES4100MP) in combination with CE leads to complete phase inversion (Fig. 2b).

The difference in morphology depends on the molecular weight of both polymers in the blend. An increase of the molecular weight of thermoplastic reduces the miscibility between the resin and the toughener, which accelerates the phase separation of the mixture. At the same time, the increase of molecular weight increases the viscosity of the mixture, which further slows down the phase separation. [15]. In the case of $\mathrm{CE}$ and high molecular weight PES, the process is complicated by sterical reasons that apparently prevent phase inversion and as a result the morphology stays co-continuous.

The morphology of fracture surface obtained using laser scanning microscopy for the mixture with $15 \mathrm{phr}$ of PES 2603 is shown in Fig. 3. The microcracks observed in Fig. 3a display a fragile structure of the neat CE. Fracture surface investigations of toughened blends demonstrated crack pinning and crazing toughening mechanisms but in the case of PES 4100MP and 5003MP the sedimentation layer is observed (Fig. 3b-d). As mentioned, the morphology investigation of blends with high molecular weight PES with terminate hydroxyl groups and non-functionalized 

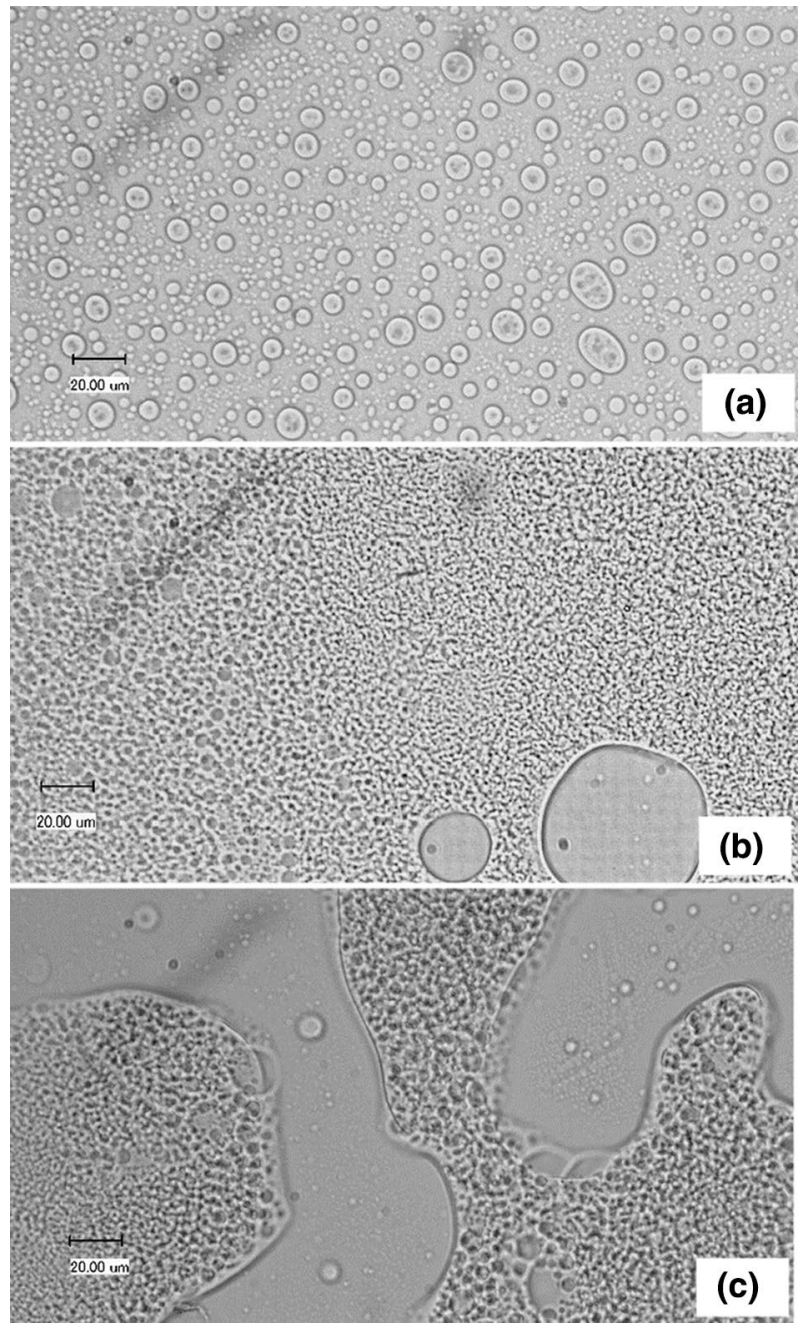

Fig. 2 Hot stage microscopy data at $260{ }^{\circ} \mathrm{C}$ for CE-15 phr PES: 2603MP (a), 4100MP (b), 5003MP (c)

PES showed a continuous structure. This likely resulted in the observed sedimentation of both tougheners in the cured cyanate ester matrix regardless of PES content.

As a result of the reaction between -OH groups of the PES and Cyanate ester, an H-bonding interaction likely occurs (Fig. 4). This influences the swelling of the PES particles in the matrix. At the same time, PES5003 due to its high molecular weight contains lower amounts of $\mathrm{OH}$ groups, which leads most probably to a dual-phase morphology. In the case of low molecular weight bisphenol A (BADCy) cyanate ester, it was shown that in BADCy-PES 5003MP blends with amounts of PES below $20 \%$ phase separation occurs with the formation of particles having a diameter of 5 $\mu \mathrm{m}$. Above $20 \%$ PES particles appear not to be bonded to the matrix [8]. In our case, 
Fig. 3 Fracture surface of the neat CE (a) and CE- 15 phr PES blends: 2603MP (b), 4100MP (c), 5003MP (d)
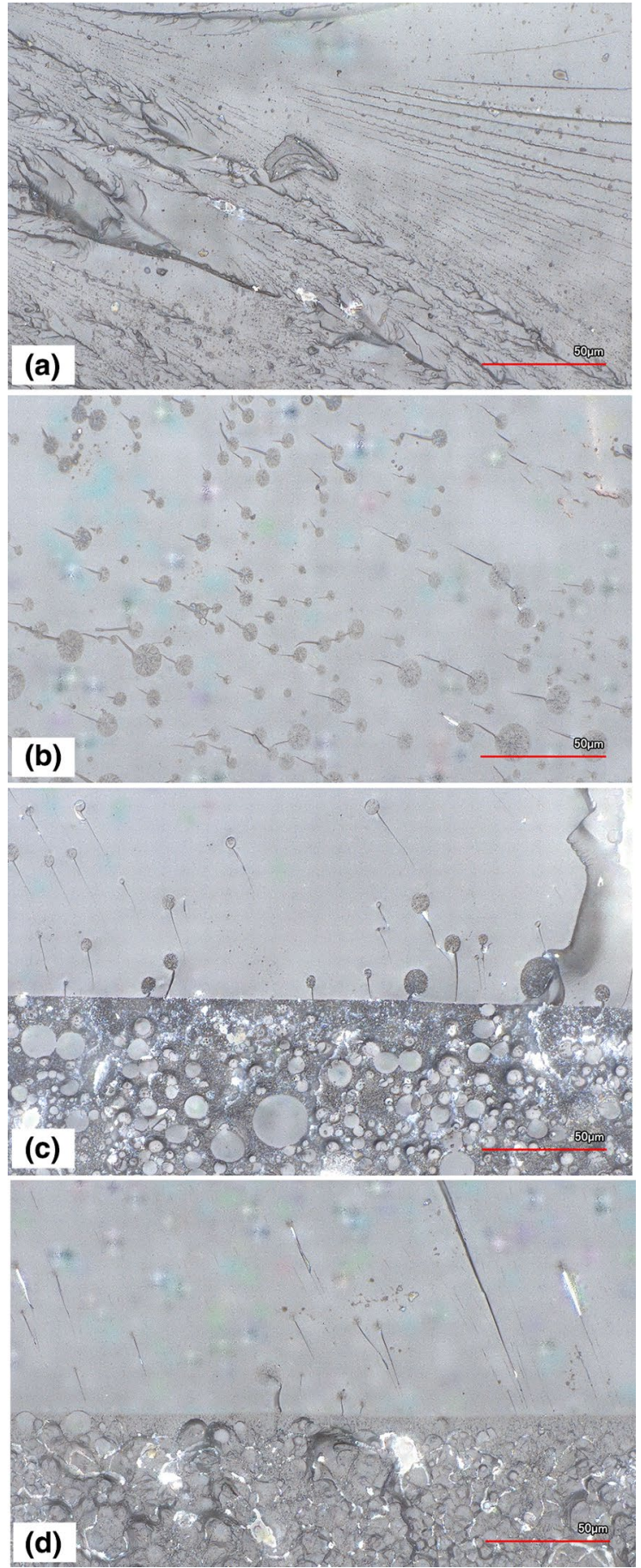


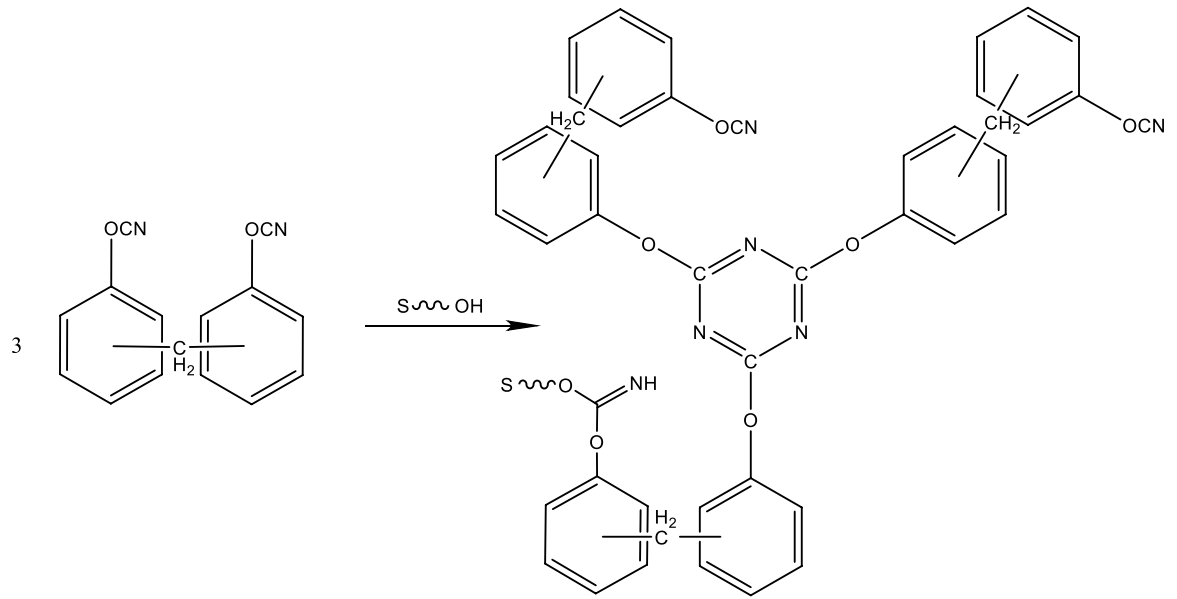

Fig. 4 Possible crosslinking of cyanate ester with polyethersulfone via hydroxyl groups

novolac CE has a higher molecular weight than BADCy, and microscopy investigations indirectly indicate that strong hydrogen bonding influences the morphology of the blend.

\section{Viscosity measurements}

Viscosity of blends neat CE and CE/PES2603 with different content of the toughener was measured in the oscillation mode at three temperatures: 30,80 and $120{ }^{\circ} \mathrm{C}$ (Fig. 5). These temperatures were chosen to estimate the best impregnation conditions and the content of PES since they represent typical temperatures in the composite processing. Usually, the recommended viscosity of the resin for prepreg manufacturing should be around $10^{5} \mathrm{~Pa}$ s at room temperature with proper tackiness and $1 \mathrm{~Pa} s$ at impregnation temperature $\left(80-120^{\circ} \mathrm{C}\right)$. The results show that the studied

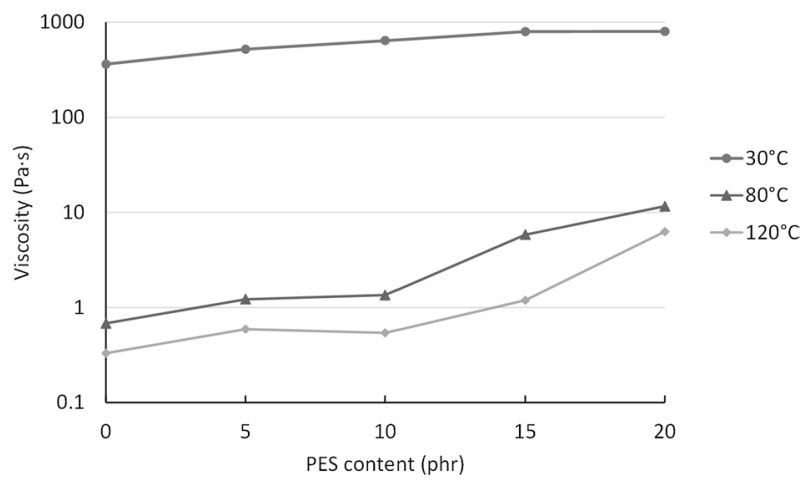

Fig. 5 Viscosity of CE-PES2603MP for various content of toughener at different temperatures 


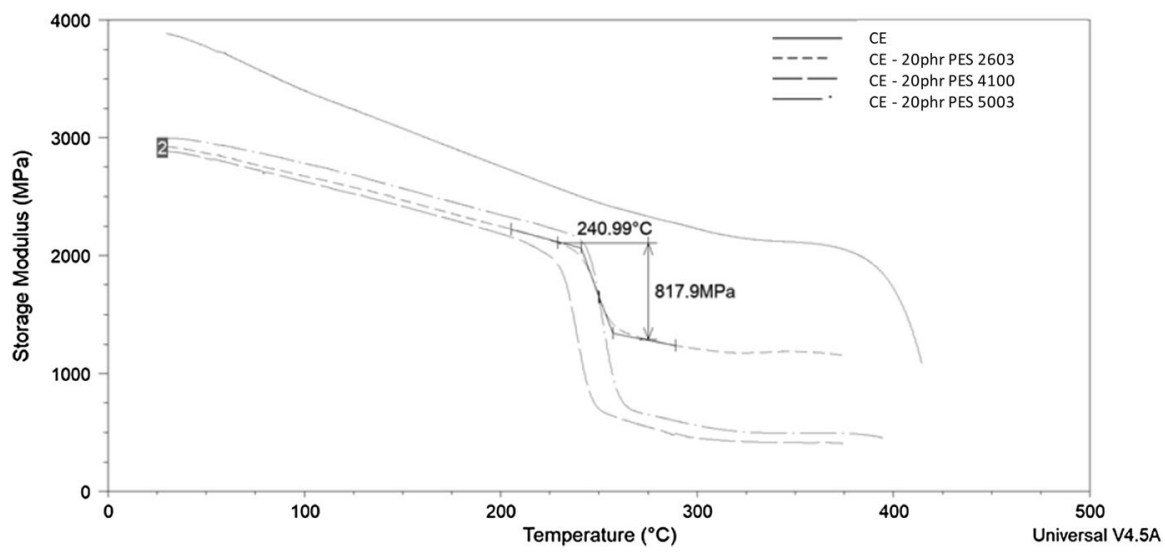

Fig. 6 DMA curves of CE with $20 \mathrm{phr}$ of PES 2603MP, 4100MP and 5003MP

Table $3 \mathrm{Tg}$ onset and storage modulus drop (\%) of neat CE and CE-PES (20 phr) blends

\begin{tabular}{lll}
\hline System & Tg onset, ${ }^{\circ} \mathrm{C}$ & $\Delta \mathrm{E}, \%$ \\
\hline $\mathrm{CE}$ & -1390 & - \\
CE-PES 2603 & $241 / 390$ & 30 \\
CE-PES 4100 & $232 / 390$ & 74 \\
CE-PES 5003 & $242 / 390$ & 70 \\
\hline
\end{tabular}

$\mathrm{CE} / \mathrm{PES}$ blends stay in the required viscosity range at room temperature. Studies at impregnation temperature show that the best choice for a blend would be either 10 phr of PES while processing at $80{ }^{\circ} \mathrm{C}$ or $15 \mathrm{phr}$ at $120^{\circ} \mathrm{C}$. Investigation of thermal and mechanical properties can give the complete picture and will lead to the final decision.

\section{Thermal properties}

DMA data show the initial storage moduli for toughened systems, which are lower than the value for neat CE (Fig. 6). The effect of PES toughener on the glass transition temperature of the investigated blends was also different. In general, there are several approaches of $T_{\mathrm{g}}$ determination, as $\tan \delta$, onset or end point of storage modulus curve. In aerospace applications, the onset $\mathrm{T}_{\mathrm{g}}$ determination is most common. The neat resin possesses the onset temperature at around $390{ }^{\circ} \mathrm{C}$. Incorporating $20 \mathrm{phr}$ of PES results in a reduction of onset temperature to values corresponding to a $\mathrm{T}_{\mathrm{g}}$ of the PES. In the case of PES 2603MP, the drop of storage modulus is approximately $30 \%$ of the initial value; whereas, in the case of PES $4100 \mathrm{MP}$ and $5003 \mathrm{MP}$ at approximately $240{ }^{\circ} \mathrm{C}$, the drop of the storage modulus comes to more than 50\% (Table 3). That correlates with the morphology data when sedimentation 


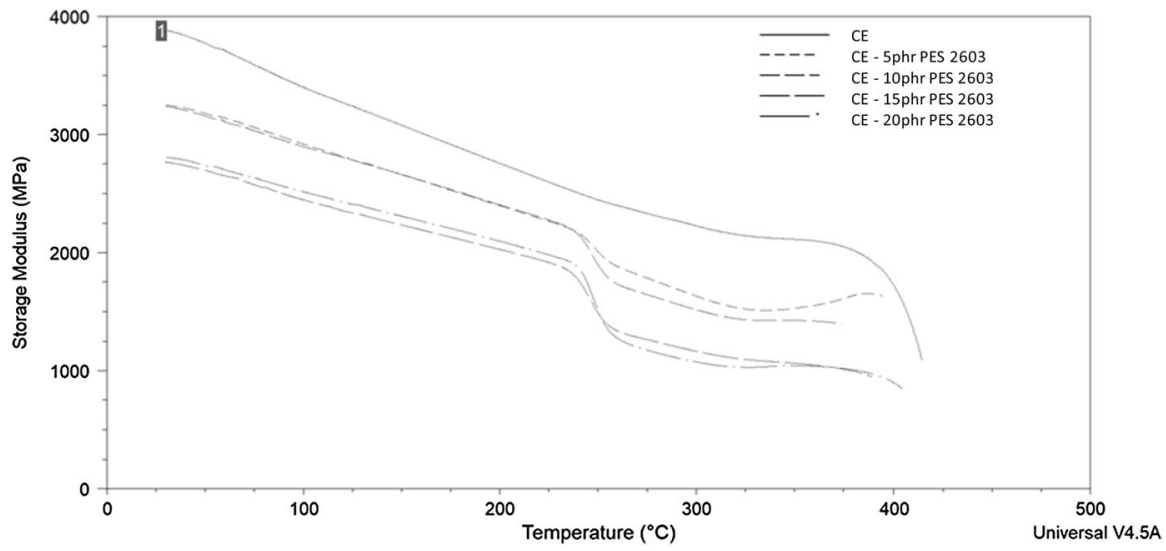

Fig. 7 DMA curves of CE blends with different content of PES 2603MP

Table 4 Flexural properties of neat CE and CE-PES blends.

\begin{tabular}{lll}
\hline System & Ef, MPa & $\sigma f, \mathrm{MPa}$ \\
\hline CE & $3802 \pm 99$ & $45.3 \pm 8.6$ \\
CE-5phr PES 2603 & $3578 \pm 149$ & $46.5 \pm 8.1$ \\
CE-10phr PES 2603 & $3483 \pm 132$ & $53.1 \pm 11.9$ \\
CE-15phr PES 2603 & $3299 \pm 143$ & $54.6 \pm 13.8$ \\
CE-20phr PES 2603 & $3275 \pm 139$ & $54.7 \pm 12.6$ \\
\hline
\end{tabular}

of high molecular weight PES was observed. Such difference also can be explained by strong hydrogen bonding formation in the case of PES 2603MP (Fig. 4).

Investigation of PES 2603MP content on the storage modulus drop is presented in Fig. 7. Initial storage modulus values are similar for 5 and $10 \mathrm{phr}$ PES (3200 MPa) and for 15 and $20 \mathrm{phr}(2800 \mathrm{MPa})$. The same trend in modulus drop is observed. Taking that into account as well as processability of the planning prepreg manufacturing, 15 phr of PES was suggested as an optimal content. Also, in case of reinforced composites the fiber will make the major contribution and this drop will be even more insignificant.

\section{Mechanical properties}

Flexural tests showed low sensitivity for CE brittle matrix (Table 4). According to [16], the values of flexural modulus $\left(E_{\mathrm{f}}\right)$ and $\left(\sigma_{\mathrm{f}}\right)$ strength of PES are 2550 and $129 \mathrm{MPa}$, respectively. With the increase of the PES content, the flexural modulus slightly decreased and strength had higher values.

Mechanical properties of CE-PES composites characterized by fracture toughness $K_{1 C}$ and fracture energy $G_{1 \mathrm{C}}$ is given in Fig. 8 . 


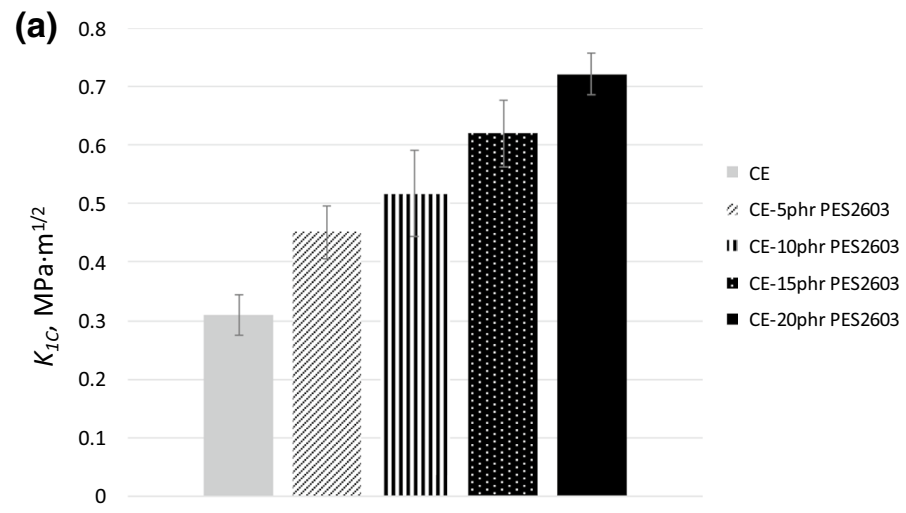

(b) 140

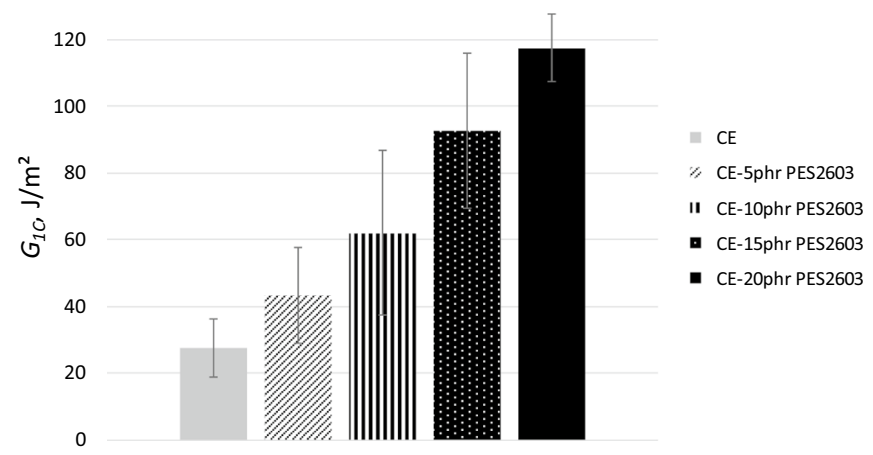

Fig. 8 Fracture toughness (a) and Fracture energy (b) values for blends with different PES content

With the increase of the PES content, the expected improvement of fracture toughness of cyanate ester matrix is observed. For $20 \mathrm{phr}$ of PES $K_{1 C}$ increased to 0.72 from $0.31 \mathrm{MPa} \mathrm{m}^{1 / 2}$ for the neat resin while $G_{1 C}$ increased to 117 from $27 \mathrm{~J}$ $\mathrm{m}^{2}$. Such improvements can be explained by forming phase separated and inverted structures. Since in the case of PES4100MP and 5003MP sedimentation occurred, no adequate improvement of mechanical properties was expected.

\section{Conclusions}

The morphology, thermal and mechanical properties of cyanate ester-polyethersulfone blends depending on the molecular weight and content of thermoplastic toughener were investigated. Increases in molecular weight of the thermoplastic toughener lead to phase separation, which causes a reduction of glass transition temperature of the blend to the value of $T_{g}$ of PES. Depending on the content of PES, the minor drop of storage modulus allows considering such systems for high temperature composites applications. 
Fracture surface investigations demonstrated crack pinning and crazing toughening mechanisms. SENB analysis showed that $20 \mathrm{phr}$ of polyethersulfone with $-\mathrm{OH}$ end groups lead to $132 \%$ improvement in fracture toughness. Thermal, mechanical and rheology tests allowed to determine the optimal content of the toughener of $15 \mathrm{phr}$ of PES suitable for the prepreg manufacturing.

In the next steps, we investigate and present results of carbon fiber composites based on the developed toughened cyanate ester system.

Funding Open access funding provided by FHNW University of Applied Sciences and Arts Northwestern Switzerland.

Acknowledgements This project has received funding from the European Union's Horizon 2020 research and innovation programme under grant agreement No. 769178 (SuCoHS project).

Open Access This article is licensed under a Creative Commons Attribution 4.0 International License, which permits use, sharing, adaptation, distribution and reproduction in any medium or format, as long as you give appropriate credit to the original author(s) and the source, provide a link to the Creative Commons licence, and indicate if changes were made. The images or other third party material in this article are included in the article's Creative Commons licence, unless indicated otherwise in a credit line to the material. If material is not included in the article's Creative Commons licence and your intended use is not permitted by statutory regulation or exceeds the permitted use, you will need to obtain permission directly from the copyright holder. To view a copy of this licence, visit http://creativecommons.org/ licenses/by/4.0/.

\section{References}

1. Läpple M, Zimmermann E, Buser S, Müller A (2020) Cyanate ester based adhesive and method for producing cyanate ester based adhesive. U.S. Patent Application No. 16/339,098.

2. Liu J, Fan W, Lu G, Zhou D, Wang Z, Yan J (2019) Semi-interpenetrating polymer networks based on cyanate ester and highly soluble thermoplastic polyimide. Polymers 11(5):862-872

3. Hamerton I, Barton JM, Chaplin A, Howlin BJ, Shaw SJ (2001) The development of novel functionalised aryl cyanate esters. Part 2. Mechanical properties of the polymers and composites. Polymer 42(6):2307-2319

4. Gu X, Zhang Z, Yuan L, Liang G, Gu A (2016) Developing high performance cyanate ester resin with significantly reduced postcuring temperature while improved toughness, rigidity, thermal and dielectric properties based on manganese-Schiff base hybridized graphene oxide. Chem Eng J 298:214-224

5. Mondragon I, Solar L, Nohales A, Vallo CI, Gomez CM (2006) Properties and structure of cyanate ester/ polysulfone/organoclay nanocomposites. Polymer 47(10):3401-3409

6. Wooster TJ, Abrol S, MacFarlane DR (2005) Polymeric toughening of particle filled cyanate ester composites. Macromol Mater Eng 290(10):961-969

7. Woo EM, Su CC, Kuo JF, Seferis JC (1994) Model with experimental evidences for the morphology of binary blends of a thermosetting polycyanate with thermoplastics. Macromolecules 27:5291-5296

8. Kinloch AJ, Taylor AC (2003) The toughening of cyanate-ester polymers: part II Chemical modification. J Mater Sci 38(1):65-79

9. Hwang JW, Park SD, Cho K, Kim JK, Park CE, Oh TS (1997) Toughening of cyanate ester resins with cyanated polysulfones. Polymer 38(8):1835-1843

10. Inamdar A, Cherukattu J, Anand A, Kandasubramanian B (2018) Thermoplastic-toughened hightemperature cyanate esters and their application in advanced composites. Ind Eng Chem Res 57(13):4479-4504

11. Recalde IB, Recalde D, García-Lopera R, Gómez CM (2005) FTIR isothermal cure kinetics and morphology of dicyanate ester resin/polysulfone blends. Eur Polym J 41(11):2635-2643

12. Blanco I, Cicala G, Faro CL, Recca A (2003) Improvement of thermomechanical properties of a DGEBS/DDS system blended with a novel thermoplastic copolymer by realization of a semi-IPN network. J Appl Polym Sci 88(13):3021-3025 
13. Brooker RD, Kinloch AJ, Taylor AC (2012) The morphology and fracture properties of thermoplastictoughened epoxy polymers. J Adhes 86(7):726-741

14. Guenthner AJ, Davis MC, Lamison KR, Yandek GR, Cambrea LR, Groshens TJ, Mabry JM (2011) Synthesis, cure kinetics, and physical properties of a new tricyanate ester with enhanced molecular flexibility. Polymer 52(18):3933-3942

15. Hwang JW, Cho K, Yoon TH, Park CE (2000) Effects of molecular weight of polysulfone on phase separation behavior for cyanate ester/polysulfone blends. J Appl Polym Sci 77(4):921-927

16. High heat resistance amorphous polymer. https://www.sumitomo-chem.co.jp/sep/english/products/pdf/ pes_technote_e.pdf

Publisher's Note Springer Nature remains neutral with regard to jurisdictional claims in published maps and institutional affiliations. 